\title{
Protocolo para Intubação Orotraqueal (IOT) segura na pandemia da COVID-19, no cenário do Sistema Único de Saúde.
}

\section{RESUMO}

Introdução: Os procedimentos realizados durante a abordagem inicial das vias aéreas podem gerar aerossóis que aumentam o risco de transmissão. Dessa forma, os profissionais de saúde que tratam pacientes com COVID-19 têm maior risco de contrair a doença e portanto, algumas medidas de precaução devem ser tomadas. Objetivo: Compartilhar recomendações atualizadas relacionadas à autoproteção da equipe multidisciplinar ao intubar suspeitas ou pacientes com COVID-19.Metodologia: Tratase de um estudo descritivo, exploratório, com abordagem qualitativa. O percurso metodológico envolveu três etapas: 1- Criação do fluxograma; 2- Oferta das sessões educativas; 3- Avaliação da satisfação pelo público. Este estudo foi realizado na unidade de queimados de um hospital de referência para COVID-19, da Secretaria de Estado de Saúde do Distrito Federal. Resultados: Foi realizado um treinamento em que foram discutidas as informações contidas neste fluxograma e em outros protocolos construídos pela equipe. Conclusão: O uso do fluxograma para a intubação orotraqueal na Unidade de Queimados teve uma boa aplicabilidade, qualificando a prática clínica sobre as medidas preventivas e terapêuticas seguras para o paciente e equipe.

PALAVRAS-CHAVE: Educação em Saúde; Protocolo Clínico; Indução e Intubação de Sequência Rápida; Intubação; Coronavírus.

\section{Protocol for Safe Orotracheal Intubation (IOT) during COVID-19 pandemic, in the scenario of the Unified Health System.}

\begin{abstract}
Introduction: Procedures performed during the initial airway approach may generate aerosols that increase the risk of transmission. Thus, health professionals who treat patients with COVID-19 have a higher risk of contracting the disease and therefore, some precautionary measures should be taken. Objective: To share updated recommendations related to the self-protection of the multidisciplinary team when intubating suspects or patients with COVID-19. Methodology: This is a descriptive, exploratory study with a qualitative approach. The methodological path involved three stages: 1- Creation of the flowchart; 2- Offering educational sessions; 3-Assessment of health care works satisfaction. This study was carried out in a Burn Unit of a referral center to COVID-19 patients of Federal District Health Department, using instruments available in the unified health system. Results: A training was conducted in which the information contained in this flowchart and in other protocols constructed by the team were discussed. Conclusion: The use of the flowchart for orotracheal intubation in the Burn Unit had a good applicability, qualifying clinical practice on safe preventive and therapeutic measures for the patient and team.
\end{abstract}

KEYWORDS: Health Education; Clinical Protocol; Induction and Rapid Sequence Intubation; Intubation; Coronavirus. 


\section{INTRODUÇÃO}

A pandemia mundial de doença de coronavírus (COVID-19) já afetou mais de 1.000.000 de pessoas e tirou a vida de mais de 50.000 em todo o mundo. ${ }^{1}$ A síndrome respiratória aguda grave - vírus corona - 2 (SARS - CoV - 2), que causa a COVID - 19, é um vírus corona encapsulado em ácido ribonucleico de fita simples com alto risco de contágio. Acredita-se que a transmissão ocorra principalmente por espalhamento de gotículas (partículas relativamente grandes que se depositam no ar) e contato direto com o paciente ou superfícies contaminadas. ${ }^{2}$

A pneumonia viral é a doença predominante na COVID - 19. As intervenções nas vias aéreas são necessárias principalmente para a intubação orotraqueal (IOT) e o estabelecimento de ventilação mecânica invasiva (VMI). Os procedimentos realizados durante a abordagem inicial das vias aéreas podem gerar aerossóis que aumentam o risco de transmissão. Dessa forma, os profissionais de saúde que tratam pacientes com COVID19 têm maior risco de contrair a doença e portanto, algumas medidas de precaução devem ser tomadas para evitar a disseminação do vírus ao gerenciar as vias aéreas, particularmente durante a intubação e extubação. ${ }^{1,2}$

Os profissionais de saúde estão comprometidos em aprender e participar de treinamentos de atualização para otimizar o manejo clínico da COVID-19. ${ }^{3}$ Segundo a Sociedade de Terapia Intensiva (2020), as recomendações devem ser sobre a prevenção da contaminação dos profissionais, a escolha do pessoal envolvido no manejo das vias aéreas, o treinamento necessário e a seleção de equipamentos. ${ }^{2}$

Diante disso, faz-se necessário a adoção de protocolos para melhor preparo da equipe diante de um cenário de pandemia, afim de alinhar as condutas terapêuticas de forma segura para os profissionais envolvidos e também para os pacientes. O objetivo 
desse estudo é compartilhar recomendações atualizadas relacionadas à autoproteção da equipe multidisciplinar ao intubar suspeitas ou pacientes com COVID-19.

\section{MÉTODOS}

Trata-se de um estudo descritivo, exploratório, com abordagem qualitativa. $\mathrm{O}$ percurso metodológico envolveu três etapas: 1- Criação do fluxograma; 2- Oferta das sessões educativas; 3- Avaliação da satisfação pelo público. Este estudo foi realizado na unidade de queimados de um hospital de referência para atendimento ao COVID-19, da Secretaria de Saúde do Distrito Federal.

O desenvolvimento do fluxograma surgiu baseado nas necessidades relatadas pelos profissionais de saúde sobre a falta de um procedimento padrão para intubação segura dos pacientes com COVID 19. A elaboração do fluxograma foi elaborada utilizando a ferramenta online diagrams.net (drawio-app.com), desenvolvido o processo de edição e diagramação, linguagem clara e científica com os pontos mais relevantes. A segunda etapa foi a aplicação na unidade para a equipe multiprofissional, realizando encontros em diferentes turnos/horários para apresentação do fluxograma. A equipe foi composta por: médicos, fisioterapeutas, enfermeiros e técnicos de enfermagem e com participação ativa dos participantes. A última etapa foi a avaliação e feedback da equipe, para esclarecer dúvidas e adequar o desenho de forma mais objetiva para sua aplicabilidade.

\section{RESULTADOS}

O fluxograma (Figura 1) foi construído baseando-se nas informações presentes em um material da Associação Brasileira de Medicina de Emergência (ABRAMEDE) em conjunto com a Associação de Medicina Intensiva Brasileira (AMIB) ${ }^{4}$, que corroboram 
com informações presentes nas Diretrizes de consenso para o manejo das vias aéreas em pacientes com COVID-19 da Sociedade de Terapia Intensiva $(2020)^{2}$.

Foi realizado um treinamento na Unidade de Queimados em que foram discutidas as informações contidas neste fluxograma e em outros protocolos construídos pela equipe. O fluxograma foi entregue a Chefia de Enfermagem da Unidade e disponibilizado para consulta por todos os profissionais do setor.

O protocolo indicado para a IOT nesses pacientes descreve uma técnica para reduzir potencialmente a contaminação por secreções e aerossóis durante a intubação, utilizando os instrumentos Partindo do pressuposto que o profissional esteja utilizando os equipamentos de proteção individual (EPI). 
Figura 1. Fluxograma para Sequência de Intubação Orotraqueal na COVID-19

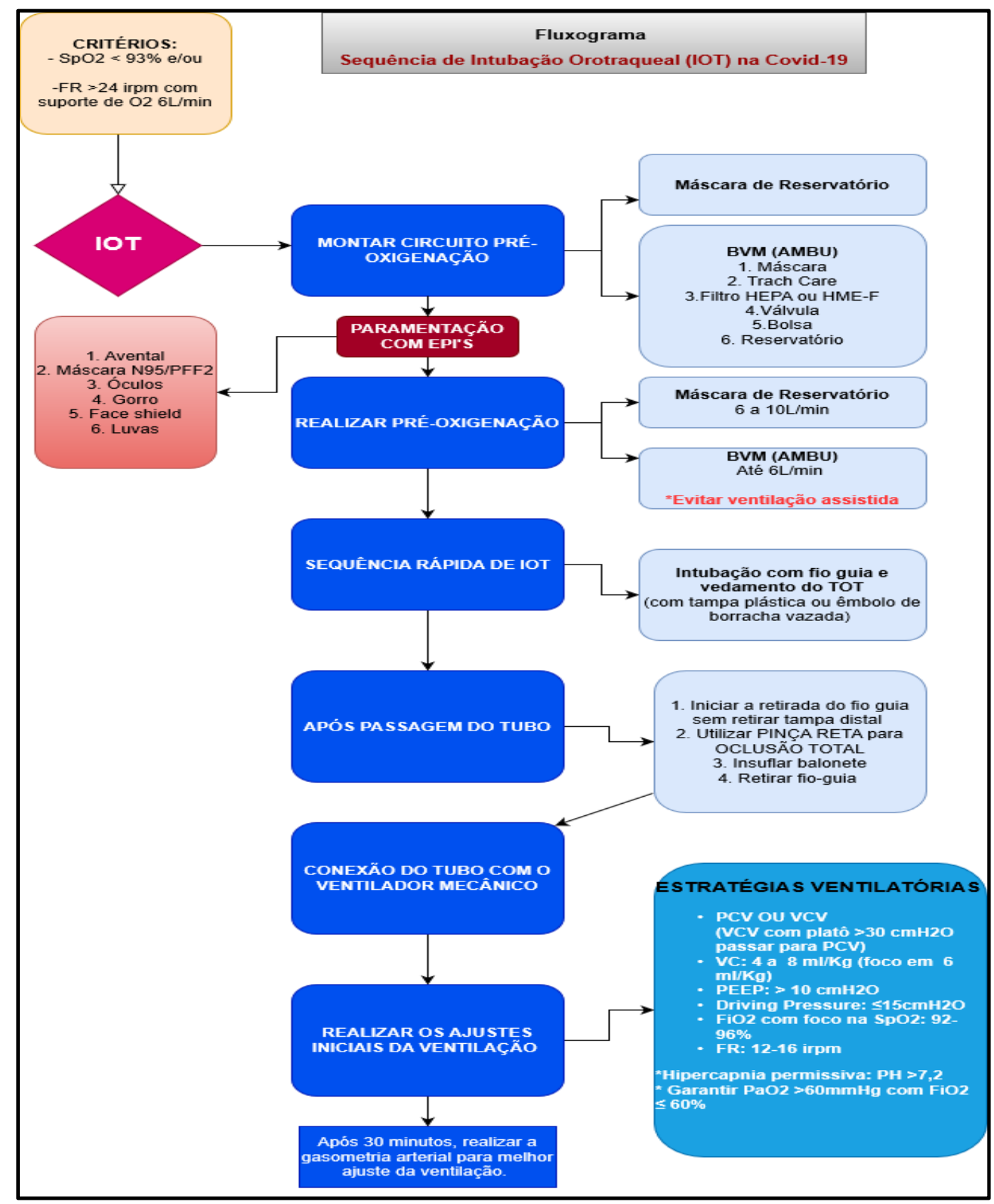

Legendas: SpO2- Saturação periférica de Oxigênio; FR Frequência Respiratória; O2- Oxigênio; IOTIntubação Orotraqueal; BVM- Bolsa Válvula Máscara; EPI- Equipamento de Proteção Individual; TOT- tubo orotraqueal; PCV- Ventilação controlada à Pressão; VCV- Ventilação controlada a Volume; VC- Volume Corrente; PEEP- Pressão Expiratória Final Positiva; FiO2- Fração Inspirada de Oxigênio; pH:potencial Hidrogeniônico; PaO2- Pressão arterial de Oxigênio. 


\section{Antes de iniciar o processo de intubação}

Um tubo orotraqueal (TOT) é preparado com a extremidade do êmbolo preto de uma seringa padrão de $20 \mathrm{~mL}$ presa ao conector distal como uma tampa de cobertura. Deve ser feito um orifício na extremidade do êmbolo para permitir a passagem do fio guia, impedindo a propagação de partículas à medida que o TOT entra nas vias aéreas. ${ }^{2,4}$

Deve-se preparar o material de pré-oxigenação com unidade "máscara - trach care - filtro HEPA ou HME F- válvula - bolsa - reservatório" (utilizar o fluxo de oxigênio $<15 \mathrm{l} / \mathrm{min}$, volume suficiente de forma titulada para manter a bolsa inflada durante a respiração) com cuidado para evitar vazamentos ou utilizar máscara com reservatório não-reinalante com fluxo entre 6 a 10 1/min de forma a manter o reservatório inflado durante a respiração. ${ }^{2,4}$

\section{Durante a intubação}

Utilizar a sequência rápida de intubação. Evitar ventilação assistida com BVM, pela produção de aerossóis e risco de contaminação do ambiente e dos profissionais. ${ }^{2,4}$

Proceder a intubação com fio guia e vedamento do tubo orotraqueal (TOT). O êmbolo deve permanecer no lugar. Após inflar o balonete do TOT, o fio guia deve ser parcialmente removido, garantindo que o êmbolo continue no mesmo lugar. Utilizar uma pinça reta para promover a oclusão total do tubo. ${ }^{2,4}$

\section{Após a intubação orotraqueal}

Deve-se retirar a pinça reta e realizar a conexão diretamente no ventilador. A confirmação da localização do tubo deve ser feita com capnografia, evitando o uso de BVM e estetoscópio pelos riscos de contaminação e por serem menos eficazes. ${ }^{2,4}$ Logo após, realizar os ajustes iniciais de acordo com as estratégias ventilatórias recomendadas pela Sociedade de Medicina Intensiva e Sociedade Europeia de Medicina Intensiva 
(2020). ${ }^{5}$ Após um período de até 30 minutos, coletar uma gasometria arterial para melhor ajuste da ventilação mecânica.

\section{DISCUSSÃO}

O enfrentamento da pandemia do novo coronavírus faz parte das principais metas da Saúde Pública por meio de ações voltadas para a população ou para grupos com maior risco de contaminação, como os profissionais de saúde. Porém, pouco se discute sobre as condições e organização do trabalho desses profissionais, prevalecendo, até o momento, protocolos com recomendação de medidas individuais (higiene e uso de equipamentos de proteção), fundamentais, mas insuficientes para o controle geral da disseminação e da exposição ao vírus. ${ }^{6}$

No entanto, a despeito da COVID-19, em pouco mais de três meses, pode-se encontrar na literatura científica grande número de publicações sobre a doença, nos diversos tipos de estudos científicos como experimentos in vitro, relatos de casos, uso de potenciais medicamentos e até revisão sistemática. No cenário atual, denota-se a relevância do assunto nas principais bases de dados. Por outro lado, a capacidade de leitura com senso crítico para concluir sobre o que melhor se aplica à realidade de cada um é limitada, não só pelo pouco tempo, mas também por falta de conhecimento sobre metodologia científica por parte dos profissionais da saúde. ${ }^{7}$

Em meio a esse bombardeio de informações e inúmeras publicações na literatura em pouco espaço de tempo, o que pode levar ao conflito entre achados apresentados até o momento, podendo gerar uma dificuldade na adoção das medidas terapêuticas corretas para o enfretamento da doença por parte dos profissionais que não tenham domínio sobre a avaliação da qualidade metodológica dos estudos. Correia et al. (2020), salienta ainda 
que esta tarefa é árdua e pode ser marcada por controvérsias, visto que o que hoje parece ser lógico, amanhã poderá ser contestado. Afinal, as verdades transitórias sempre rondaram a Medicina. ${ }^{7}$

Diante desse contexto em que os serviços de saúde se encontram, se faz necessário a aplicação de protocolos, treinamentos e cursos que busquem minimizar os erros passíveis de serem cometidos durante uma pandemia que podem causar prejuízos tanto ao tratamento do paciente quanto à saúde dos profissionais envolvidos. Sabendo-se disso, a criação desse fluxograma teve como intuito facilitar a tomada de decisão na prática clínica baseada em evidências científicas. O fluxograma foi construído de forma que as informações ficassem de fácil entendimento e adequado à realidade da Unidade de Queimados, pensando na composição da equipe e nos materiais de disponíveis no setor.

\section{CONCLUSÃO}

O uso do fluxograma para a intubação orotraqueal na Unidade de Queimados teve uma boa aplicabilidade, qualificando a prática clínica sobre as medidas preventivas e terapêuticas seguras para o paciente e equipe, durante o enfretamento da COVID-19 baseada em evidências científicas.

\section{REFERÊNCIAS BIBLIOGRÁFICAS}

1. Editorial E. Recommendations for Endotracheal Intubation of COVID-19 Patients. 2020; 130: 1109-1110.

2. Society IC. Consensus guidelines for managing the airway in patients with

COVID-19 Guidelines from the Dif fi cult Airway Society, the Association of Anaesthetists the Intensive Care Society, the Faculty of Intensive Care Medicine 
and the Royal College of Anaesthetists. 2020; 1-15.

3. Asenjo JF. Safer intubation and extubation of patients with COVID-19. Can J Anesth Can d'anesthésie. Epub ahead of print 2020. DOI: 10.1007/s12630-02001666-9.

4. Paula A, Corrêa TD, Araujo K De. Recomendações para Intubação Orotraqueal em pacientes portadores de COVID-19. Assoc Bras Med Emergência e Assoc deMedicina Intensiva Bras 2020; Versão N.3: 15.

5. Alhazzani W, Møller MH, Arabi YM, et al. Surviving Sepsis Campaign: guidelines on the management of critically ill adults with Coronavirus Disease 2019 ( COVID - 19). Springer Berlin Heidelberg. Epub ahead of print 2020. DOI: $10.1007 / \mathrm{s} 00134-020-06022-5$.

6. Federal U, Gerais DM, Medicina F De, et al. A saúde do trabalhador e o enfrentamento da COVID-19 Worker' $\mathrm{s}$ health and the struggle against COVID19 Referências. 2020; 6369: 10-12.

7. Dei RM, Horizonte B, Janeiro R De. Os cirurgiões e a pandemia do COVID-19 . 47: $1-6$. 